\title{
Mechanism-Based Combination Treatment Dramatically Increases Therapeutic Efficacy in Murine Globoid Cell Leukodystrophy
}

\author{
Jacqueline A. Hawkins-Salsbury, ${ }^{1}$ Lauren Shea, ${ }^{1}$ @Xuntian Jiang, ${ }^{1}$ Daniel A. Hunter, ${ }^{2}$ A. Miguel Guzman, ${ }^{4}$ \\ Adarsh S. Reddy, ${ }^{1}$ Elizabeth Y. Qin, ${ }^{1}$ Yedda Li, ${ }^{1}$ Steven J. Gray, ${ }^{5}$ Daniel S. Ory, ${ }^{1}$ and Mark S. Sands ${ }^{1,3}$ \\ Departments of ${ }^{1}$ Internal Medicine, ${ }^{2}$ Surgery, and ${ }^{3}$ Genetics, Washington University School of Medicine, St Louis, Missouri 63110, ${ }^{4}$ Department of \\ Pathology, St Louis University School of Medicine, St Louis, Missouri 63104, and ${ }^{5}$ Department of Ophthalmology, University of North Carolina School of \\ Medicine, Chapel Hill, North Carolina 27599
}

Globoid cell leukodystrophy (GLD, Krabbe disease) is a lysosomal storage disease (LSD) caused by a deficiency in galactocerebrosidase (GALC) activity. In the absence of GALC activity, the cytotoxic lipid, galactosylsphingosine (psychosine), accumulates in the CNS and peripheral nervous system. Oligodendrocytes and Schwann cells are particularly sensitive to psychosine, thus leading to a demyelinating phenotype. Although hematopoietic stem-cell transplantation provides modest benefit in both presymptomatic children and the murine model (Twitcher), there is no cure for GLD. In addition, GLD has been relatively refractory to virtually every experimental therapy attempted. Here, Twitcher mice were simultaneously treated with CNS-directed gene therapy, substrate reduction therapy, and bone marrow transplantation to target the primary pathogenic mechanism (GALC deficiency) and two secondary consequences of GALC deficiency (psychosine accumulation and neuroinflammation). Simultaneously treating multiple pathogenic targets resulted in an unprecedented increase in life span with improved motor function, persistent GALC expression, nearly normal psychosine levels, and decreased neuroinflammation. Treating the primary pathogenic mechanism and secondary targets will likely improve therapeutic efficacy for other LSDs with complex pathological and clinical presentations.

Key words: dysmyelination; gene therapy; globoid cell leukodystrophy; Krabbe disease; lysosomal storage disease

\section{Introduction}

Globoid cell leukodystrophy (GLD, Krabbe Disease) is an inborn error of metabolism resulting from a deficiency in the lysosomal enzyme galactocerebrosidase (GALC; Wenger et al., 2001). Loss of GALC activity results in the accumulation of a cytotoxic lipid, galactosylsphingosine (psychosine), in the CNS and peripheral nervous system leading to a dysmyelinating phenotype (Miyatake and Suzuki, 1973). The currently available treatment for GLD is hematopoietic stem-cell transplantation (HSCT), which provides only modest improvements if initiated before symptom onset (Krivit et al., 1998; Escolar et al., 2005; Martin et al., 2006). Therefore, the development of new and more efficacious therapeutic regimens is of the utmost importance.

\footnotetext{
Received Oct. 10, 2014; revised Feb. 23, 2015; accepted March 15, 2015.

Author contributions: J.A.H.-S. and M.S.S. designed research; J.A.H.-S., L.S., X.J., D.A.H., A.M.G., A.S.R., E.Y.Q., Y.L., S.J.G., and M.S.S. performed research; S.J.G., D.S.O., and M.S.S. contributed unpublished reagents/analytic tools; L.S., X.J., D.A.H., A.M.G., A.S.R., E.Y.Q., Y.L., D.S.O., and M.S.S. analyzed data; J.A.H.-S. wrote the paper

This work was funded in part by grants from the National Institutes of Health (R01 NS084861) and The Legacy of Angels Foundation.

The authors declare no competing financial interests.

Correspondence should be addressed to Dr Mark S. Sands, Washington University School of Medicine, Department of Internal Medicine, Campus Box 8007, 660 South Euclid Avenue, St Louis, M0 63110. E-mail: msands@dom.wustl.edu.

DOI:10.1523/JNEUROSCI.4199-14.2015

Copyright $\odot 2015$ the authors $\quad 0270-6474 / 15 / 356495-11 \$ 15.00 / 0$
}

An authentic mouse model of GLD, the Twitcher mouse, has been available for more than three decades (Kobayashi et al., 1980). This mouse mimics the human disease and has a rapid and severe disease course (Suzuki and Suzuki, 1983). Despite the availability of the Twitcher mouse, development of effective therapies has been slow. Virtually all single-therapy approaches, including BMT (Yeager et al., 1984), gene therapy (Lin et al., 2005, 2007; Galbiati et al., 2009; Gentner et al., 2010; Reddy et al., 2011; Rafi et al., 2012), substrate reduction (LeVine et al., 2000; Biswas and LeVine, 2002), antioxidants (Hawkins-Salsbury et al., 2012a), steroids (Kagitani-Shimono et al., 2005; Luzi et al., 2009), enzyme replacement (Lee et al., 2005; Qin et al., 2012), and neuronal (Pellegatta et al., 2006) or mesenchymal (Ripoll et al., 2011) progenitor cells, have met with minimal to modest success.

GLD is a complex disease, involving the primary pathogenic mechanism and secondary consequences. Therefore, it is not surprising that single therapeutic approaches provide limited efficacy. Combination therapies that target both primary and secondary mechanisms have been more successful. Intracranial gene therapy targeting the primary defect synergized with bone marrow transplantation (BMT) to nearly triple the lifespan of the Twitcher mouse (Lin et al., 2007). Subsequent improvements in the route of gene therapy delivery further extended the life span (Reddy et al., 2011).

Substrate reduction therapy for LSDs decreases the rate of accumulation of undegraded metabolites by reducing the synthe- 
sis of the enzyme substrates. This can be accomplished in GLD with L-cycloserine, which broadly decreases the synthesis of sphingolipids, including psychosine (Sundaram and Lev, 1985; LeVine et al., 2000). L-cycloserine alone significantly improves lifespan in the Twitcher mouse to $\sim 57 \mathrm{~d}$ (LeVine et al., 2000) and synergizes with BMT to increase lifespan to $\sim 112 \mathrm{~d}$ (Biswas and LeVine, 2002).

Here we show that targeting the primary pathogenic mechanism and two secondary consequences of GALC deficiency using diverse therapeutic approaches dramatically increases treatment efficacy in the Twitcher mouse. Mice were treated from an early age with "triple therapy" consisting of BMT, adeno-associated virus 2/5 (AAV2/5)-mediated gene therapy, and substrate reduction with L-cycloserine. Interestingly, each approach increased efficacy in a synergistic manner, resulting in an unprecedented increase in lifespan and persistent clinical/behavioral improvements. Simultaneously targeting distinct pathogenic pathways may be the most effective way to treat complex inherited metabolic disorders, such as lysosomal storage diseases.

\section{Materials and Methods}

Experimental design. Treated and untreated Twitcher mice, as well as untreated controls were used in this study. Twitcher mice were treated with CNS-directed gene therapy on postnatal day (P)2, BMT on P3, and $\mathrm{L}$-cycloserine three times a week starting on P5. Experimental and control animals of both sexes were randomly assigned to groups for analysis at predetermined time points ( $n=3-6$ animals/time point) or for life span and behavioral analyses ( $n=10-14$ animals/group). The number of animals/group was based on previous experience with this model and the specific assays, as well as power calculations. Quantitative biochemical analyses (GALC activity, psychosine measurements, cytokine/chemokine levels) were performed in duplicate on tissues from three to six animals, depending on the assay. Semiquantitative histomorphometry was performed on at least three representative sections/animal from at least three animals/group. The photography settings were kept constant for all images. ANOVA was used for group comparisons with Bonferroni correction for pairwise comparisons. Student's $t$ test was used to compare the means of two groups. Significant differences in life span were determined by log-rank test. Differences were deemed significance at a $p$ value of $<0.05$.

Experimental animals. Animals were housed at Washington University School of Medicine under the supervision of MSS. The Institutional Animal Care and Use Committee at Washington University School of Medicine approved all animal protocols. Heterozygous Twitcher (GALC \pm ) mice on a C57BL/6 background were obtained from the Jackson Laboratory, and heterozygote by heterozygote matings were used to generate the homozygous Twitcher $\left(\mathrm{GALC}^{-1-}\right)$ mice used in this study. Genotypes were determined on P1 by PCR as previously described (Sakai et al., 1996; Lin et al., 2005). Hematopoietic stem cell donors were sexmatched syngenic GALC $^{+/+}$mice expressing GFP under control of the CAGGS promoter (Okabe et al., 1997). Mice were housed under standard conditions with ad libitum access to food and water and were maintained on a $12 \mathrm{~h}$ light/dark cycle. Only mice that survived to weaning at $28 \mathrm{~d}$ were included in this study.

Viral vector. The AAV 2/5 vector was prepared by the Virus Vector Core Facility at the Gene Therapy Center of the University of North Carolina. The viral vector consisted of the murine GALC cDNA under control of the CMV enhancer and chicken $\beta$-actin promoter. The murine cDNA was followed by the $3^{\prime}$-untranslated region from the rabbit $\beta$-globin gene. The single-stranded AAV2 vector was pseudotyped with an AAV5 capsid. Virus was produced using a triple-transfection method in HEK293 cells and was recovered using sequential step and continuous $\mathrm{CsCl}$ gradients, followed by dialysis in PBS containing $350 \mathrm{~mm} \mathrm{NaCl}$ and $5 \%$ sorbitol. Viral titers were determined using dot blot hybridization as previously described (Gray et al., 2011). Virus was diluted to a final concentration of $10^{12}$ viral particles per milliliter in Lactated Ringer's solution and stored at $-80^{\circ} \mathrm{C}$.
Intracranial and intrathecal injections. AAV2/5-GALC was administered to the nervous system on P2-P3. Intracranial injections were performed by hand using the exact same coordinates as previously described (Reddy et al., 2011). Briefly, the mice were immobilized by hypothermia and the injection site cleaned with $70 \% \mathrm{EtOH}$. Each brain hemisphere received three, $2 \mu \mathrm{l}\left(10^{12}\right.$ viral particles per $\left.\mathrm{ml}\right)$ injections, one in the forebrain, one in the thalamus, and one in the cerebellum. Virus was also administered intrathecally at the same time. To prepare the virus for intrathecal injection, $15 \mu \mathrm{l}$ of virus $\left(10^{12}\right.$ viral particles per $\left.\mathrm{ml}\right)$ was mixed with $3 \mu$ l of trypan blue. To load the syringe a total of $15 \mu$ l of this mixture was drawn up. The mouse was restrained and a needle inserted into the spinal column approximately midway along the back. A successful injection was defined as the presence of blue dye in both the cerebellum and sacrum. The animals were warmed and returned to the mothers. A $50 \mu \mathrm{l}$ Hamilton syringe fitted with a 32 gauge needle was used for all injections.

Bone marrow transplantation. Animals receiving BMT were exposed to 400 rads of total body irradiation from a ${ }^{137} \mathrm{Cs}$ source on the day following gene therapy administration (P3-P4). Mice were injected intravenously (Sands and Barker, 1999) with $10^{6}$ nucleated donor bone marrow cells immediately after irradiation. Following this myelo-reductive conditioning regimen, treated animals had donor chimerism of $5-30 \%$ at $36 \mathrm{~d}$ as determined by flow cytometry for GFP.

L-cycloserine treatment. Treatment with subcutaneous L-cycloserine began on P5-P7 and continued three times/week for the life of the animal. L-cycloserine was diluted in PBS fresh each day, and then filter sterilized before injection. Animals received $25 \mathrm{mg} / \mathrm{kg}$ L-cycloserine until $\mathrm{P} 28$, and $50 \mathrm{mg} / \mathrm{kg}$ for the rest of their life.

Psychosine measurements. Psychosine was measured as previously described. Briefly, one brain hemisphere or two sciatic nerves from a single mouse were homogenized in $0.04 \mathrm{M}$ citric acid. Fifty microliters of each sample was added to $20 \mu \mathrm{l}$ of $\mathrm{N}, \mathrm{N}$-dimethylpsychosine $(250 \mathrm{ng} / \mathrm{ml})$ internal standard and $200 \mu \mathrm{l} \mathrm{MeOH}$. Samples were vortexed and centrifuged, and then the supernatant collected. This extraction was repeated on the remaining pellet and the supernatants pooled. Psychosine concentrations were obtained using a column-switching LC-MS/MS method. Detection was achieved using an AB SCIEX 4000QTRAP tandem mass spectrometer (Applied Biosystems/MDS Sciex) using ESI in the positive ion mode along with multiple reaction monitoring. Analyst software (v1.5.1, Applied Biosystems/MDS Sciex) was used for the data analysis. The calibration curves (analyte peak area/internal standard peak area for $y$-axis and analyte concentration for $x$-axis) of psychosine were obtained using the least square linear regression fit $(y=a x+b)$ and a weighting factor of $1 / x^{2}$. The coefficient of determination $\left(r^{2}\right)$ was set as $>0.98$ for acceptance criteria of calibration curves.

GALC activity. Following perfusion, one brain hemisphere was homogenized in ddH2O. The homogenate was centrifuged and the supernatant collected. GALC activity was measured as previously described using a ${ }^{3} \mathrm{H}$-glactosylceramide (Lin et al., 2005). After the reaction, uncleaved substrate was removed through galactose saturated chloroform/ methanol extraction. The remaining radioactivity, in the form of free ${ }^{3} \mathrm{H}$-galactose, was measured in a scintillation counter. The specific activity of GALC enzyme was calculated as nanomoles of substrate cleaved per hour per milligram of protein.

Lifespan, body weight, and behavioral testing. Lifespan was recorded as the age of the animal on the date of death or kill. Animals were killed when they became moribund as defined as one or more of the following: losing $>25 \%$ of their maximal body weight, ataxia severe enough to impair ability to eat or drink, or lack of response to tactile stimulus. Unless otherwise noted, all animals were killed by anesthetic overdose and perfused transcardially with PBS until the liver was cleared of blood. Bodyweight was recorded for each mouse $(n=12)$ once a week. Beginning at week 3 , mice were tested every other week for performance on the rotarod and inverted wire-hang tests as previously described (Reddy et al., 2011). The maximum length of either test was $60 \mathrm{~s}$. Each animal was given at least $10 \mathrm{~min}$ to recover between trial or tests. Rotarod: mice were gently placed on a stationary rod, and then the rotation started. The rod was set to rotate at a constant 3RPM. Latency to fall was recorded. The average of three trials was recorded. Wirehang: animals were placed up- 


\section{Survival}

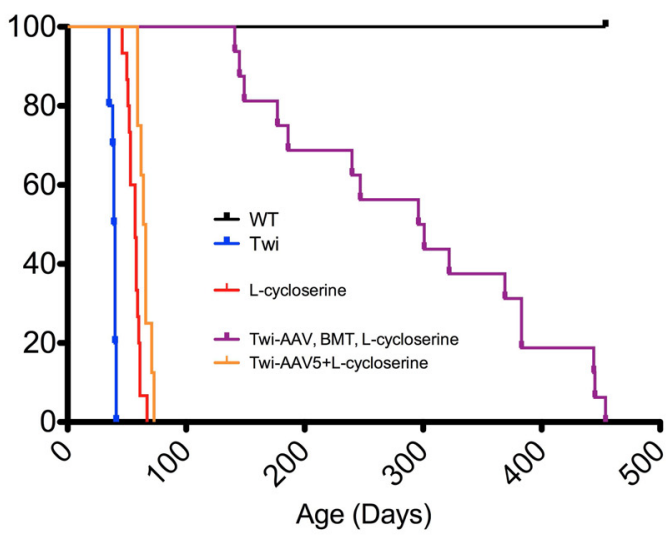

Rotarod

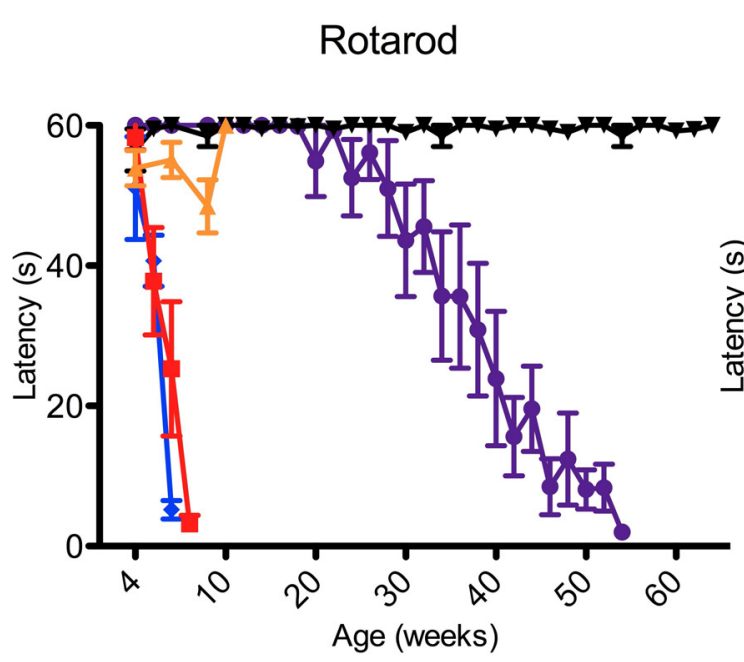

Body Weight

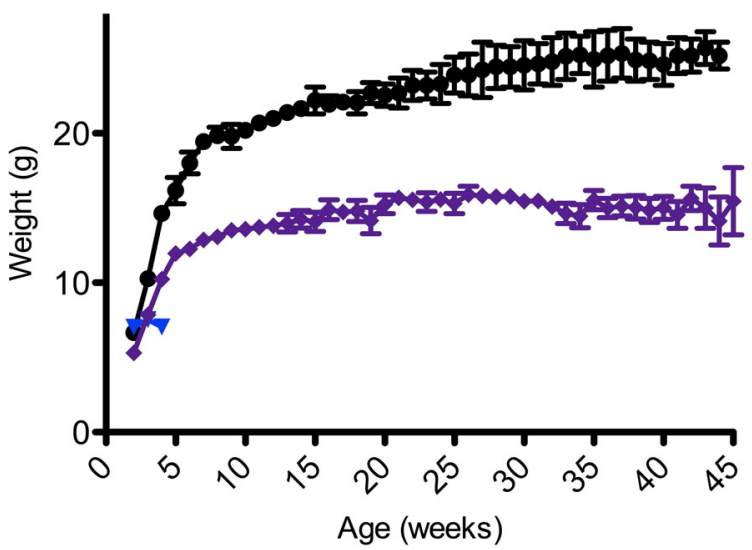

Wirehang

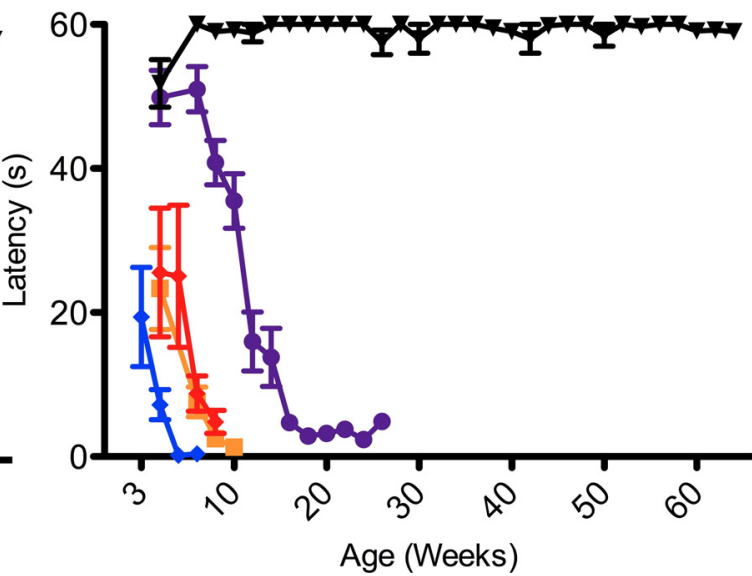

Figure 1. Tripe therapy increases lifespan and body weight, and improves motor function in Twitcher mice. Top left, Kaplan-Meier curves comparing survival of Twitcher mice treated with AAV + BMT + L-cycloserine ("triple-treatment"; $n=16)$, AAV + L-cycloserine $(n=10)$, or L-cycloserine alone $(n=9)$ to untreated Twitcher mice $(n=9)$ and untreated WT mice $(n=10)$. The median lifespan of triple-treated Twitcher mice (298.5 d, range 160-454 d) was significantly greater than that of untreated Twitcher mice (39.5 d). Triple-treated Twitcher mice also lived significantly longer than Twitcher mice treated with AAV + L-cycloserine (70 $\mathrm{d}$ ) or L-cycloserine alone $(57 \mathrm{~d}, p<0.05)$. Top right, Average body weight of triple-treated Twitcher mice was significantly greater than that of untreated Twitcher mice at $36 \mathrm{~d}$. Bottom left, Although average performance of triple-treated Twitcher mice declined with age, individual animals were able to perform the full $60 \mathrm{~s}$ test until the last few months of life. Bottom right, Average latency to fall on the wire-hang test of motor function was recorded every 2 weeks.

right on a rigid $1 / 4$ inch wire mesh screen. The screen was gently shaken to encourage gripping then turned upside down 12 inches over soft bedding. Latency to fall was recorded.

LFB/PAS staining and immunohistochemistry. Brains were harvested immediately following perfusion and either flash frozen for biochemical analyses or fixed in $4 \%$ paraformaldehyde for $24 \mathrm{~h}$ at $4^{\circ} \mathrm{C}$. The fixed brains were then moved to $30 \%$ sucrose in tris-buffered saline for an additional $24-48 \mathrm{~h}$ at $4^{\circ} \mathrm{C}$. Following cryoprotection, the brain was embedded in optimal cutting medium (Sakura Finetek), frozen on dry ice, and cryosectioned. The $16 \mu \mathrm{m}$ sections were stained with luxol fast blue and periodic acid Schiff (LFB/PAS) as previously described (Lin et al., 2005). Additional sections were immunostained with anti-GFAP, antiCD68, or anti-GFP antibodies according to standard methods. Briefly, free-floating sections were incubated in $1 \%$ hydrogen peroxide to quench endogenous peroxidase activity. Sections were then blocked in normal goat serum and incubated in primary antibody. Sections were next incubated in the appropriate biotinylated secondary antibody, followed by incubation in Vectastain Elite ABC reagent (Vector Laboratories). Sections were developed using a $\mathrm{DAB}$ peroxidase substrate kit (Vector Laboratories). Antibodies were as follows: rabbit anti-mouse glial fibrillary acidic protein (GFAP; 1:100; Immunostar), rat-antimouse CD68 (1:1000; AbD Serotec), rabbit polyclonal anti-mouse GFP
(1:10,000; Abcam), biotinylated anti-rabbit IgG supplied with the Vectastain kit (1:200; PK-6101 Vector Laboratories), and mouse-adsorbed biotinylated anti-rat IgG (1:200; Vector Laboratories). Stained sections were mounted, dehydrated and coverslipped. Images were captured using an Olympus BX41 microscope and Olympus DP20 camera. All image capture variables were kept identical. At least three sections per animal and three animals per treatment group were analyzed for each brain area studied. Staining was quantified using ImageJ software. The percentage of total image area with staining above a set threshold value was calculated as the area fraction.

Sciatic nerve. Sciatic nerves were removed and fixed in phosphatebuffered $4 \%$ paraformaldehyde $/ 2 \%$ glutaraldehyde $(n=4-6$ per treatment group). Nerves were then incubated in osmium tetroxide, serially dehydrated in ethanol, and embedded in Araldite 502 (Polysciences). An ultramicrotome was used to prepare $1 \mu \mathrm{m}$ cross-sections, which were then stained with $1 \%$ toluidine blue dye and mounted on slides. A Hitachi CCD KP-M1AN digitizing camera mounted on a Leitz Laborlux S microscope was used for image acquisition. Histomorphometric analysis was performed using the Leco IA32 Image Analysis System as previously described (Hunter et al., 2007).

Cytokines. PBS-perfused brains ( $n=4-10$ per treatment group) were flash-frozen in liquid nitrogen, then thawed on ice and homogenized in a 


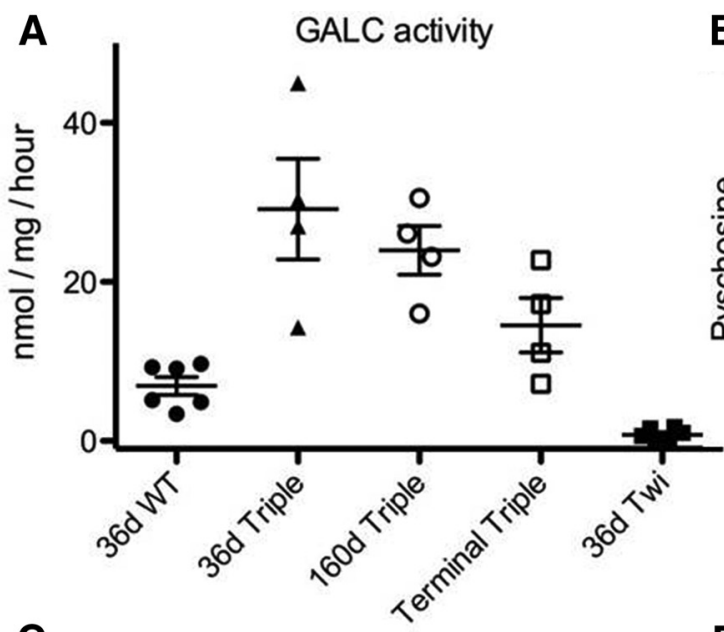

B Substrate Reduction (Brain)
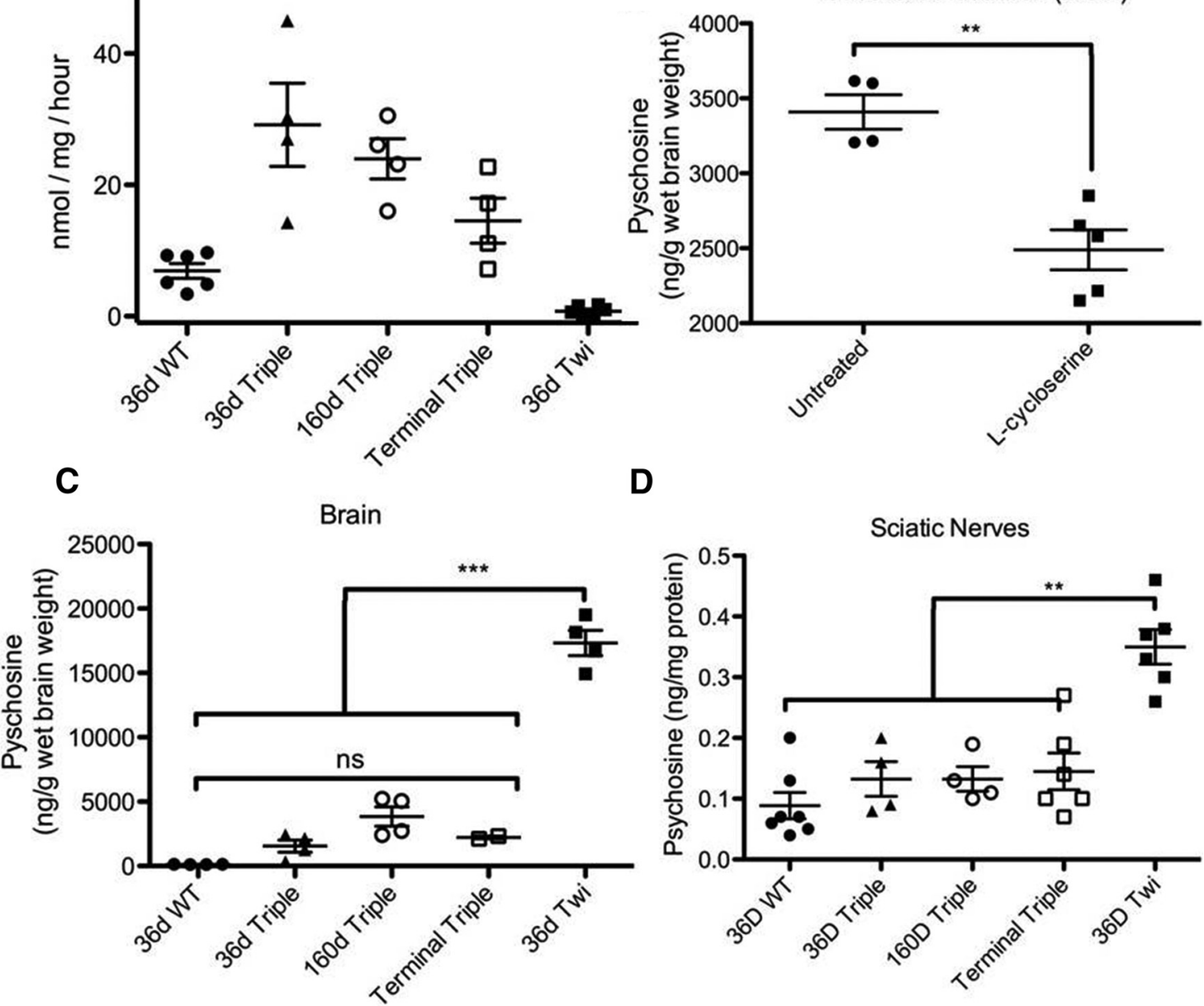

D

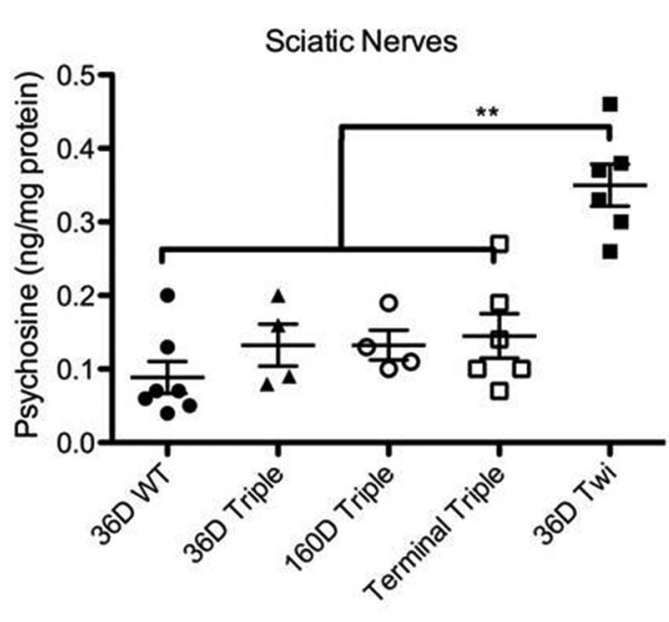

Figure 2. Triple therapy supplies persistent GALC activity and decreases psychosine accumulation in the Twitcher mouse. A, GALCactivity was increased $\sim 3.5$-fold from WT levels in triple-treated Twitcher mice at $36 \mathrm{~d}$ ( $n=4-6$ animals per group). Though a slight decrease in GALC activity was observed as the animals aged, GALC activity remained approximately twice WT levels in terminal triple-treated animals. $\boldsymbol{B}$, Thrice weekly treatment with $25 \mathrm{mg} / \mathrm{kg} \mathrm{L}$-cycloserine alone resulted in a significant reduction in brain psychosine in Twitcher mice $(n=4-5$ animals per group). C, Triple therapy significantly reduced whole-brain psychosine levels in Twitcher mice at $36 \mathrm{~d}$. Psychosine levels remained low at terminal time points $(n=4-5$ animals per group). $\boldsymbol{D}$, Sciatic nerve psychosine levels in Twitcher mice were significantly reduced by triple therapy at every time point $\left(n=4-7\right.$ animals per group; $\left.{ }^{* *} p<0.01,{ }^{* * *} p<0.001\right)$.

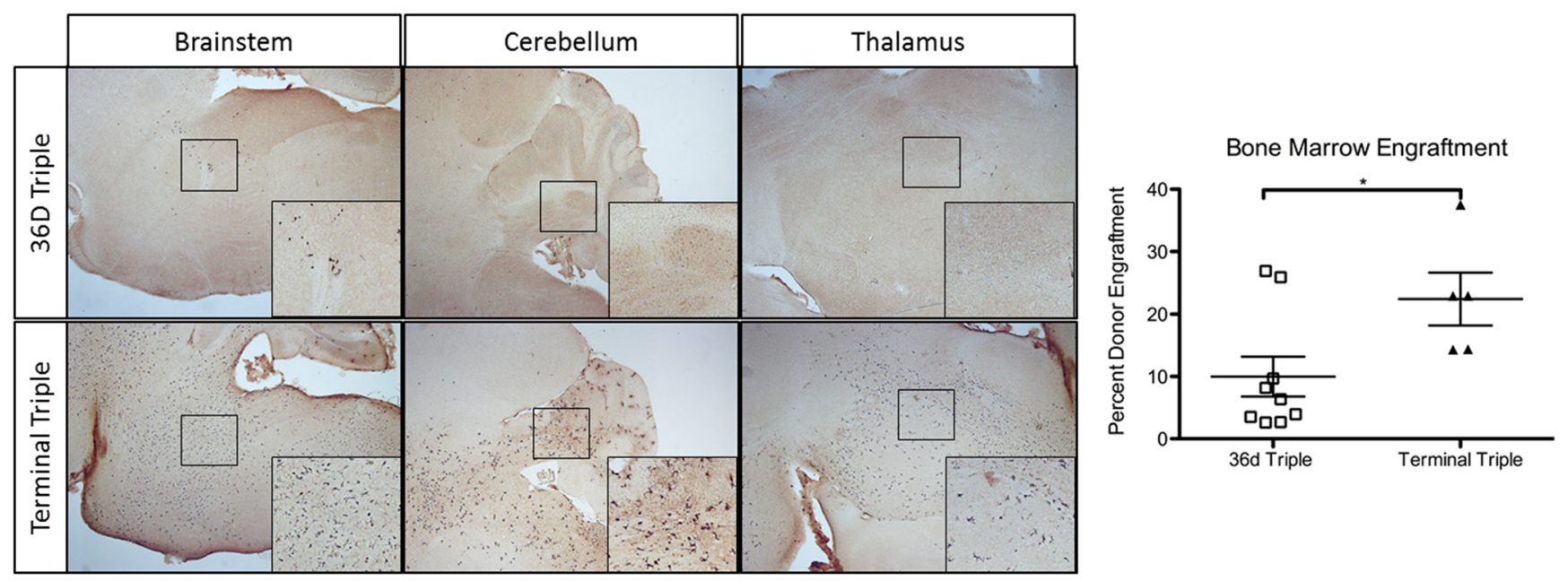

Figure 3. Persistent donor chimerism is observed in the bone marrow and brains of triple-treated Twitcher mice. Rare GFP-positive donor-derived cells were present in the brainstem, cerebellum, and thalamus of $36 \mathrm{~d}$ triple-treated mice (36D Triple). In terminal triple-treated animals (Terminal Triple) larger numbers of GFP-positive cells were observed in brainstem, cerebellum, and thalamus, among other brain regions. There is a significant increase in donor bone marrow engraftment (right) in terminal triple-treated Twitcher mice (22.4\%) compared with $36 \mathrm{~d}$ triple-treated Twitcher mice $(9.9 \%)$ as determined by flow cytometry. $\left({ }^{*} p<0.05\right)$. 


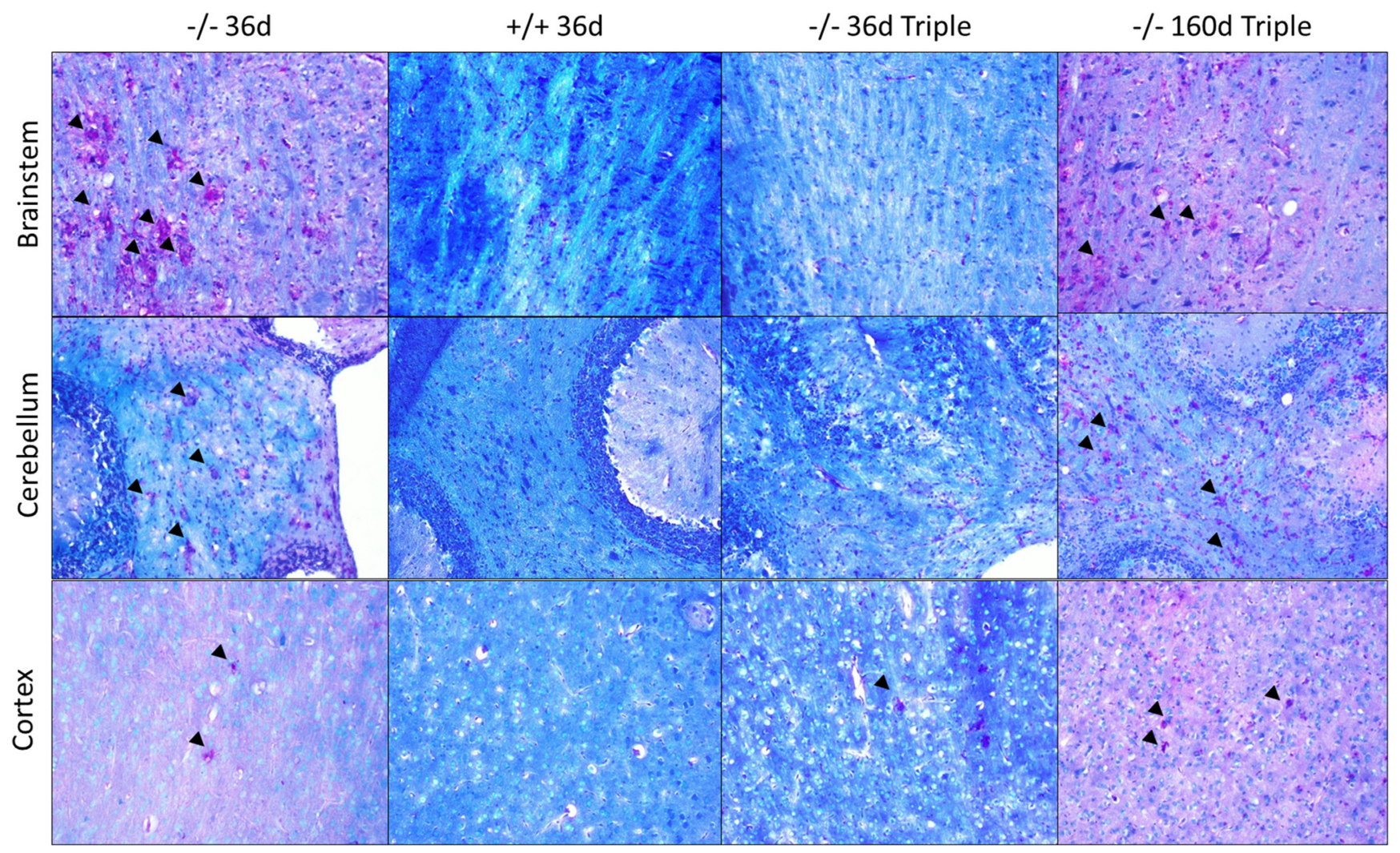

Figure 4. Myelin is relatively well preserved in younger triple-treated Twitcher mice. LFB/PSAS staining was performed to assess demyelination in the cortical, brainstem, and cerebellar white matter. No substantial myelin loss was seen in $36 \mathrm{~d}$ triple-treated mice $(-/-36 \mathrm{~d}$ triple) compared with age-matched normal controls $(+/+36 \mathrm{~d}) .0$ lder triple-treated mice $(-/-160 \mathrm{~d}$ triple) show multifocal demyelination of all three evaluated areas. The degree of demyelination is similar to that observed in the untreated mice $(-/-36 \mathrm{~d})$. Brainstem white matter tracts, followed by subcortical white matter, demonstrated more severe demyelination. In addition, a considerable decrease in PAS-positive globoid cells (arrowheads), from total absence to very rare, was seen in $36 \mathrm{~d}$ triple-treated mice $(-/-36 \mathrm{~d}$ triple) compared with untreated mice $(-/-36 \mathrm{~d})$. Older triple-treated mice $(-/-160 \mathrm{~d}$ triple) showed considerable number of PAS-positive globoid cells. However, they appeared smaller and with less PAS-positive material compared with untreated mice $(-/-36 \mathrm{~d}$; original magnification $200 \times)$.

solution containing $50 \mathrm{~mm}$ Tris-HCl, 2 mm PMSF, 2 mм EDTA, and protease inhibitors (P8340, Sigma-Aldrich) with an Eperbach ConTorque tissue homogenizer. Samples were centrifuged at $14,000 \times g$ for 4 $\min$ at $4^{\circ} \mathrm{C}$ and supernatant was sent for rodent multianalyte profile analysis (Myriad Rules-Based Medicine).

Statistical analysis. Statistical significance was calculated using a oneway ANOVA followed by Bonferroni correction for multiple comparisons to compare all treatment groups unless otherwise specified.

\section{Results \\ Lifespan}

Untreated Twitcher animals had a median lifespan of $39.5 \mathrm{~d}$ (Fig. 1 top left). We previously showed that BMT or CNS-directed AAV-mediated gene therapy initiated in newborn Twitcher mice increased the median life span to $\sim 45$ and $\sim 70 \mathrm{~d}$, respectively (Lin et al., 2007; Reddy et al., 2011). In the current study, the median lifespan for mice treated with L-cycloserine alone or L-cycloserine plus CNS-directed gene therapy is $\sim 57$ and $\sim 70 \mathrm{~d}$, respectively. In contrast, triple-treated Twitcher mice had a median lifespan of $298.5 \mathrm{~d}$, with a range of 160-454 d. Additionally, several of the treated male mice were able to impregnate normal females, whereas untreated Twitcher males are not able to breed. Treated females were housed exclusively with other females, as the effect of carrying a pregnancy was uncertain and not a goal of this study. Therefore, it remains unknown whether triple-treated Twitcher females might be fertile.

\section{Body weight}

Twitcher mice have impaired weight gain, with weight at death approximately one-half that of age-matched GALC ${ }^{+/+}$litter- mates (an average of 8 vs 16 g; Fig. 1 top right). Triple-treated mice have increased weight gain compared with untreated Twitcher mice, though not to the same extent as WT animals (maximum weight $\sim 18$ vs $25 \mathrm{~g}$ for a WT mouse). The weight of triple-treated animals was stable until immediately preceding death.

\section{Motor function}

Twitcher mice have impaired motor function as assessed through the rotarod and inverted wire-hang tests. Untreated Twitcher mice are unable to perform a test of coordination (rotarod) by 3-4 weeks of age. On average, triple-treated mice can perform the rotarod test normally until $\sim 30$ weeks of age, then slowly decline in their ability (Fig. 1 bottom left). Although the mean latency to fall steadily decreases over time, individual triple-treated mice typically perform normally (60 s) until 1.5-2 months before they die. For example, two triple-treated Twitcher mice that lived to 450 and $454 \mathrm{~d}$ of age were able to stay on the rotarod for $60 \mathrm{~s}$ until 400 and $395 \mathrm{~d}$, respectively. The inverted wire-hang is a test of grip strength and is used as a surrogate for peripheral nerve function. Untreated Twitcher mice are unable to hang onto an inverted wire screen for the full $60 \mathrm{~s}$ test even at an early stage of disease. Triple-treated animals can perform this task better than untreated mice, but still show significant deficits compared with WT animals (Fig. 1 bottom right).

\section{GALC activity}

Twitcher mice have virtually undetectable whole-brain GALC activity as measured by cleavage of the radio-labeled natural sub- 

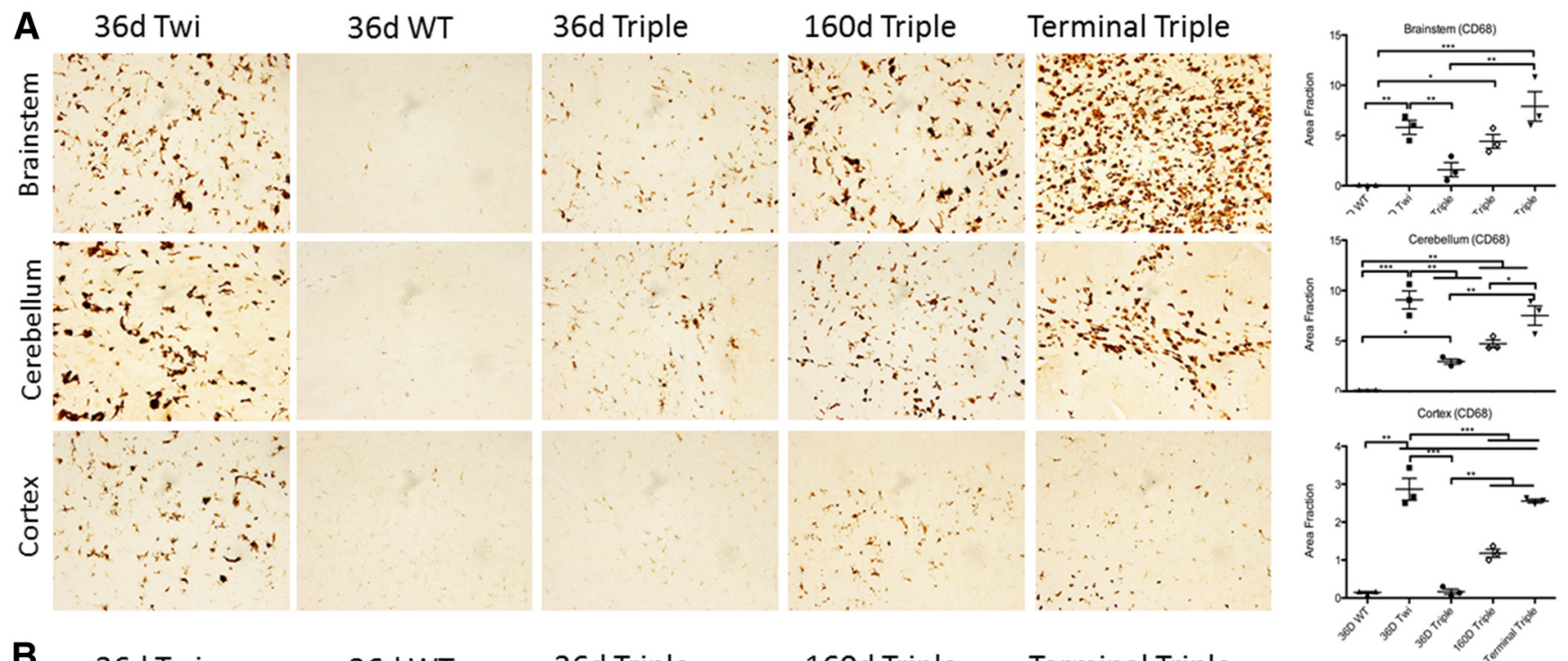
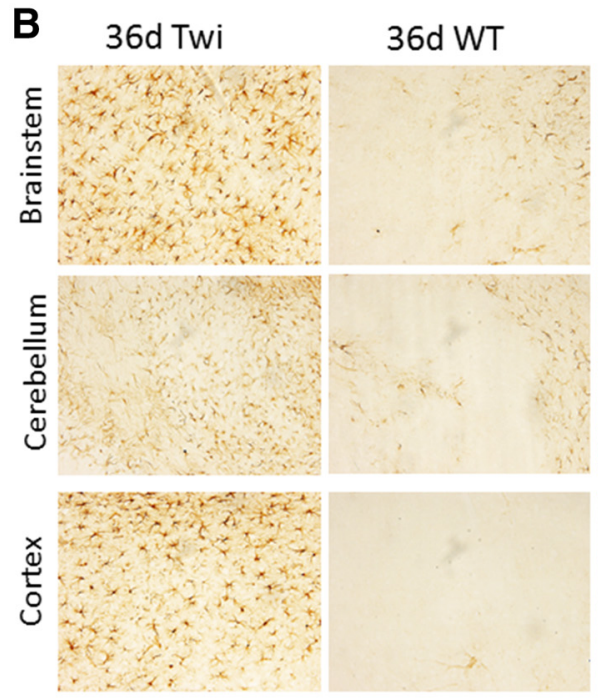

36d Triple

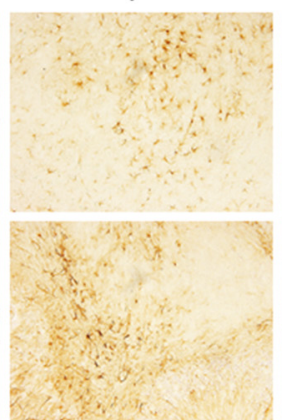

160d Triple
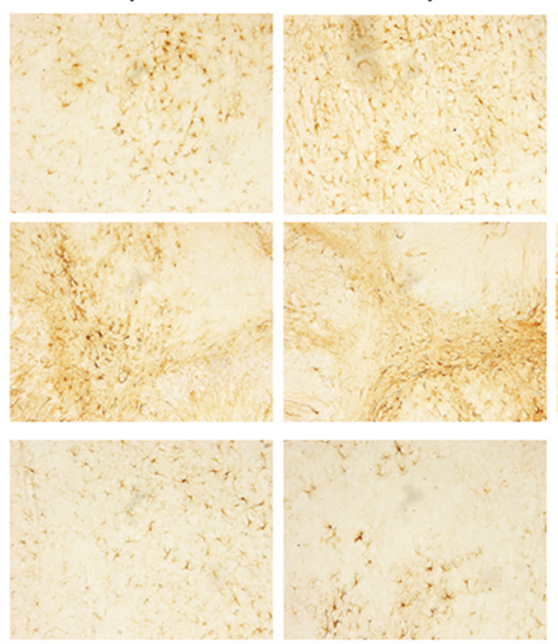

\section{Terminal Triple}
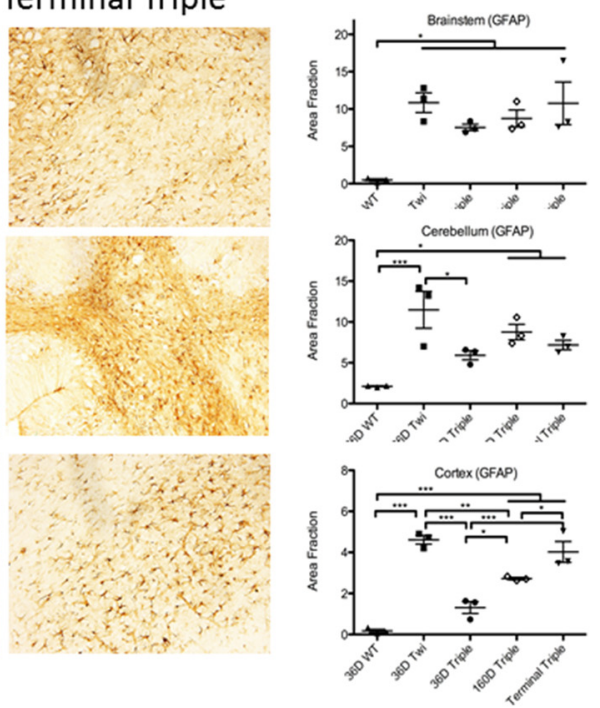

Figure 5. Microglial and astrocyte activation is reduced by triple therapy. $A, B$, Untreated Twitcher animals show large populations of CD68-positive cells relative to WT in all brain regions examined. Decreased staining is observed in $36 \mathrm{~d}$ triple-treated Twitcher brains, though levels appear to increase at $160 \mathrm{~d}$ and at terminal time points. Right, Average area fraction positive for CD68 was quantified ( $n=3$ animals per group). CD68 staining was significantly reduced in triple-treated Twitcher brains relative to untreated Twitcher brains at $36 \mathrm{~d}$. CD68 staining increased as triple-treated animals aged. A similar pattern of GFAP staining was observed for untreated and triple-treated mice. Average area fraction positive for GFAP was significantly reduced in Twitcher brains by triple therapy at $36 \mathrm{~d}$, but showed a significant increase as animals aged $\left({ }^{*} p<0.05\right.$, ${ }^{* *} p<0.01$, $\left.{ }^{* * *} p<0.001\right)$.

strate of GALC, galactosylceramide (Fig. 2A). At $36 \mathrm{~d}$, the level of whole-brain GALC activity in triple-treated Twitcher mice is 3.5-fold greater than WT animals. Although there is an apparent decrease in GALC activity as the animals age, this is not statistically significant. Even at a terminal time point, triple-treated Twitcher mice still have nearly double the WT levels of brain GALC activity.

\section{Psychosine levels}

Whole-brain psychosine levels are elevated in Twitcher mice relative to WT mice (Fig. 2B,C). Thrice-weekly injections of $\mathrm{L}$-cycloserine alone significantly reduces whole-brain psychosine (Fig. 2B). Previous studies have shown that AAV2/5-mediated gene therapy alone reduces whole-brain psychosine levels, whereas BMT alone does not (Reddy et al., 2011). As expected, triple-treated Twitcher mice also show reduced psychosine levels in the brain compared with untreated Twitcher mice (Fig. 2C). Although whole brain psychosine levels in triple-treated animals are likely higher than WT, this difference is not statistically significant. Whole-brain psychosine levels remain low throughout the lifespan of triple-treated mice, with levels indistinguishable from WT at $160 \mathrm{~d}$ and at terminal time points. Psychosine also accumulates in the sciatic nerve of Twitcher mice. This accumulation is not observed in triple-treated Twitcher mice, even at terminal time points (Fig. 2D).

\section{GFP-positive donor cell engraftment}

By $36 \mathrm{~d}$, triple-treated animals have an average of $9.9 \%$ (range $=$ 5-30\%) donor chimerism in the bone marrow (Fig. 3, Bone Marrow Engraftment). There is a significant increase in average donor bone marrow engraftment $(22.4 \%)$ in terminal triple-treated mice. Engraftment of donor microglia in the brain is a much slower process (Kennedy and Abkowitz, 1997). At 36 d, only rare GFP-positive cells are observed in the brains of triple-treated mice. In contrast, numerous GFP-positive cells can be seen in 

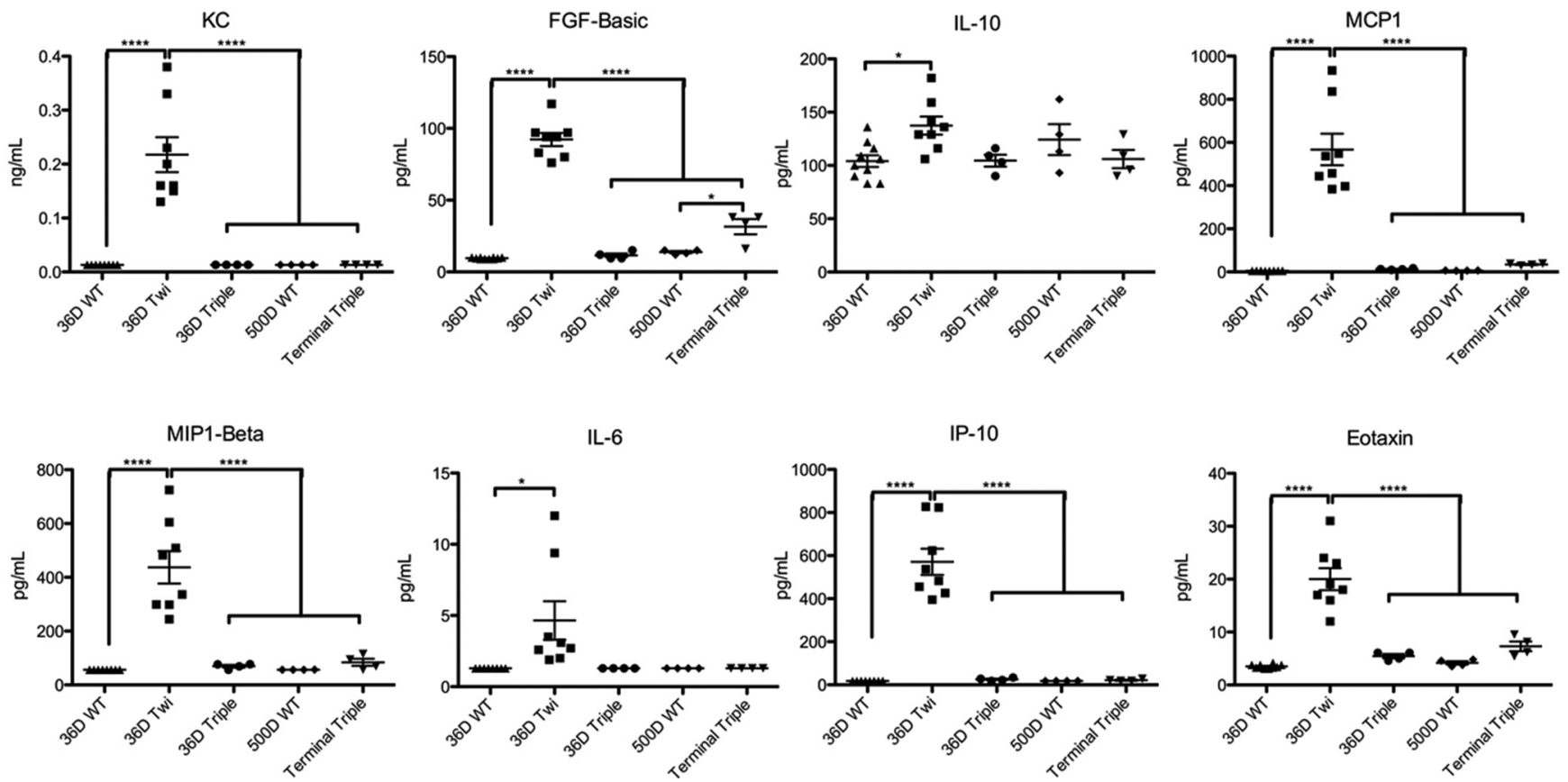

Figure 6. Triple therapy reduces cytokine/chemokine expression in the Twitcher brain. Inflammatory cytokines/chemokines were increased in untreated Twitcher brains relative to WT at $36 \mathrm{~d}$ ( $n=4-10$ animals per group). Triple therapy resulted in a significant decrease in proinflammatory cytokines/chemokines. The levels remained indistinguishable from WT at terminal time points, with the exception of a slight increase in FGF-basic. IL-10, a cytokine with anti-inflammatory functions, was significantly increased in untreated Twitcher brains relative to WT. Triple-treated Twitcher brains showed IL-10 levels that were indistinguishable from WT at $36 \mathrm{~d}$ and at terminal time points $\left({ }^{*} p<0.05,{ }^{* * *} p<0.0001\right)$.

terminal animals, particularly in the brainstem, cerebellum, and thalamus (Fig. 3).

\section{Myelination and "globoid cell" infiltration}

There is a substantial decrease in LFB staining in the cortex, brainstem, and cerebellum of untreated 36-d-old Twitcher mice compared with age-matched normal controls (Fig. 4). There is also an increase in the number of PAS-positive globoid cells in the untreated 36-d-old Twitcher mice compared with the normal controls. The level of LFB staining in 36-d-old triple-treated Twitcher mice is comparable to the normal control. Although there are still some globoid cells present in the 36-d-old tripletreated Twitcher mice it is greatly reduced compared with age-matched Twitcher mice. The intensity of LFB staining in 160d-old triple-treated Twitcher mice is comparable to the 36-d-old untreated Twitcher mice. Although the number of PAS-positive cells in 160-d-old triple-treated Twitcher mice is comparable with 36-d-old untreated Twitcher mice, the cells appear smaller with less PAS-positive material.

\section{Microglial and astrocyte activation}

As previously reported, an increased number of CD68-positive macrophages and activated microglia are found in the brains of Twitcher mice compared with WT controls at $36 \mathrm{~d}$ (Lin et al., 2007; Reddy et al., 2011). Triple treatment dramatically decreased CD68 staining at $36 \mathrm{~d}$ (Fig. 5A). However, CD68 staining steadily increases as the treated mice age. A similar trend is observed for GFAP-positive activated astrocytes (Fig. 5B). Astrocytosis is diminished in triple-treated Twitcher brains at $36 \mathrm{~d}$, but increases as the animals age.

\section{Cytokine/chemokine levels}

To further characterize the effect of triple therapy on neuroinflammation in the Twitcher brain, cytokine/chemokine levels were measured in whole-brain homogenates. Several proinflammatory cytokines and chemokines were increased in Twitcher brains relative to WT at $36 \mathrm{~d}$ (Fig. 6). Expression of these immune mediators was reduced to WT levels in $36 \mathrm{~d}$ triple-treated mice. The majority of these cytokines remained low throughout the lifespan of the treated animals, with only FGF-basic showing a slight increase in terminal mice. Interestingly, IL-10, a cytokine with immune suppressive effects, was minimally elevated in untreated Twitcher brains, and was reduced to WT levels following triple therapy.

\section{Peripheral neuropathy}

Untreated Twitcher mice demonstrate severe hindlimb weakness, such that hind limbs are essentially paralyzed when mice reach a terminal time point at $\sim 40 \mathrm{~d}$ of age. Untreated Twitcher sciatic nerves are grossly swollen and display several features that are characteristic of Krabbe disease, including myelin loss, increased interstitial edema, cellular infiltration, and decreased axon density (Fig. 7). Quantitative histomorphometric analyses showed a significant decrease in axon density and a trend toward decreased myelin width in untreated Twitcher mice (Fig. 7). These changes are not prevented by triple therapy, and sciatic nerve pathology gets significantly worse over the lifespan of treated mice. Sciatic nerves from terminal triple-treated mice also show a unique histological pattern consisting of concentric swirls of myelin and connective tissue reminiscent of "onion bulb" formations. This pattern was not observed in $36 \mathrm{~d}$ triple-treated animals (Fig. 7).

\section{Discussion}

GLD has proven refractory to most therapeutic interventions. This is likely due to the complex nature of this disease, involving the primary and multiple secondary pathogenic mechanisms. In the current study, we targeted the primary defect in Twitcher 
mice with AAV-mediated, CNS-directed gene therapy (Fig. 8). In addition, we targeted two secondary consequences of GALC deficiency, psychosine accumulation and neuroinflammation, with substrate reduction therapy and BMT, respectively (Fig. 8). This multipronged approach resulted in the greatest increase in lifespan to date, with triple-treated Twitcher mice living to a median of $\sim 300$ $\mathrm{d}$ and several mice living $>450 \mathrm{~d}$. Based on the increases in life span when applied singly, the combination of these three treatments should result in a median lifespan of $\sim 90 \mathrm{~d}$ if they interacted in an additive fashion. The unprecedented degree of synergy suggests that combining therapies directed at multiple targets can lead to breakthroughs in the treatment of complex metabolic disorders.

Although we obtained profound synergistic effects, a second-generation AAV vector, AAV2/5, was used in the current study. Newer generation AAV vectors (e.g., AAVrh10 or AAV2/9) mediate higher levels of transduction and have a broader distribution in the mouse brain (Foust et al., 2009; $\mathrm{Hu}$ et al., 2010). Therefore, they would be expected to increase efficacy even further. Another limitation in the current study is the fact that neonatal mice can only be exposed to sublethal, nonablative conditioning radiation ( $\sim 400$ rads; Sands et al., 1993). Consequently, the triple-treated mice had donor hematopoietic chimerism of only 5-30\%. It will be important to determine whether higher levels of engraftment significantly increases efficacy in this combination treatment paradigm. Finally, recent single-treatment studies using sophisticated approaches and the latest generation gene transfer vectors have reported median lifespans in the Twitcher mice of only 80-120 d (Gentner et al., 2010; Rafi et al., 2012). However, those approaches would likely increase treatment efficacy if used in combination.

Although this intensive therapeutic regimen is efficacious, it is not without side effects. In our experience, mice are particularly sensitive to L-cycloserine in the weeks immediately following gene therapy and BMT. We observed a relatively high $(30-50 \%)$ mortality before weaning if mice were injected with $50 \mathrm{mg} / \mathrm{kg}$ L-cycloserine during this time. Nearly no mortality was observed if mice were given a dose of 25 $\mathrm{mg} / \mathrm{kg}$ during the same period. This sensitivity was related to the combination of treatments, as it was not seen in animals treated with $50 \mathrm{mg} / \mathrm{kg}$ L-cycloserine alone. Similarly, we have observed minimal mortality in animals treated with gene therapy, BMT or a combination of the two. It is likely that L-cycloserine, which inhibits the synthesis of many glucosylated and galactosylated lipids in addition to psychosine, alters the normal balance of sphingolipids and reduces the ability of the brain to respond to the stress associated with conditioning radiation and intracranial injection of virus. The reduction of many sphingolipids and the
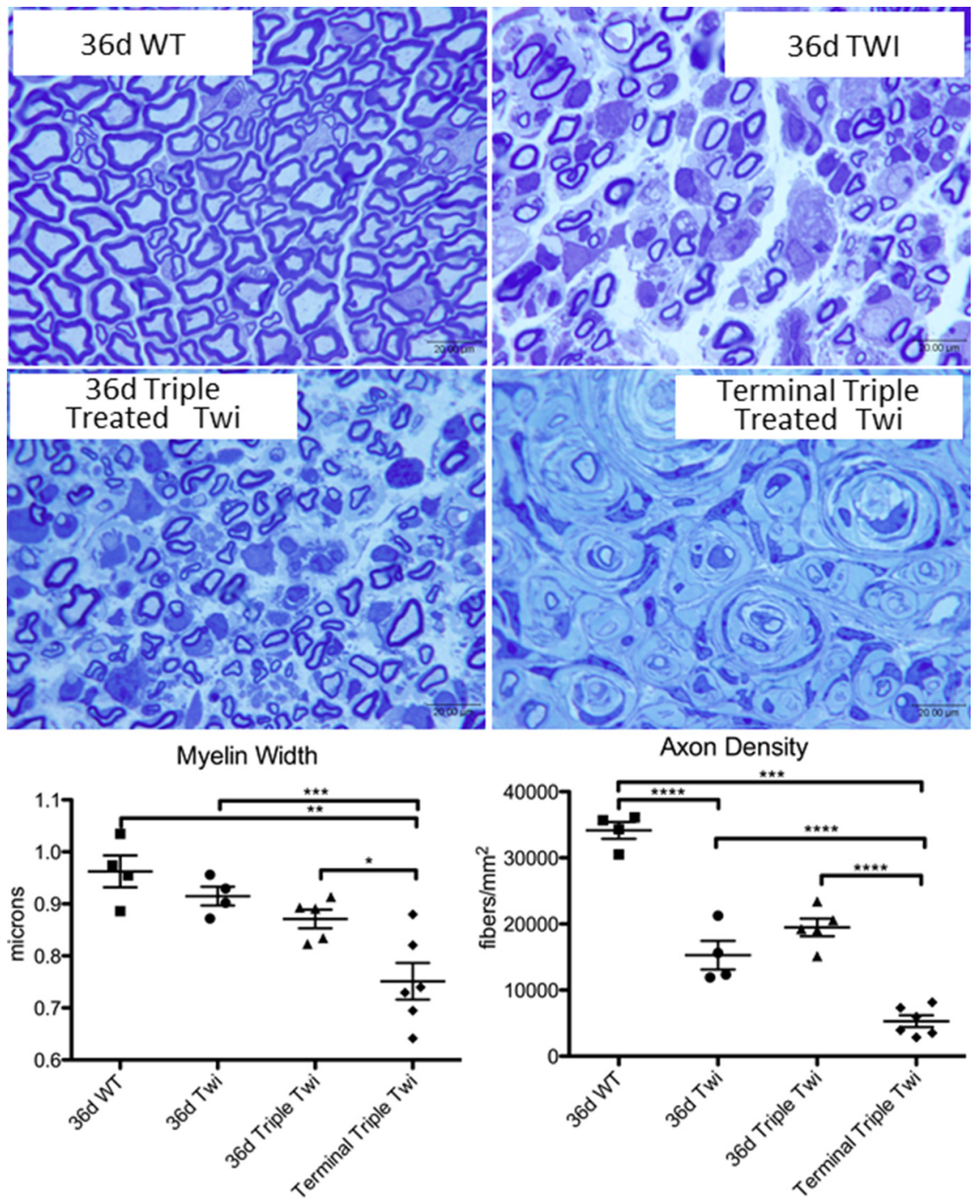

Figure 7. Peripheral neuropathy is not corrected by triple therapy. Untreated WT sciatic nerves show compact, myelinated fibers (top left). Untreated Twitcher sciatic nerves are characterized by increased interstitial edema, cellular infiltration, decreased myelination, and decreased axon density (top right). At $36 \mathrm{~d}$, nerves from triple-treated and untreated Twitcher mice appear sciatic nerves relative to WT. These changes were not reversed by triple therapy and were more severe in terminal triple-treated sciatic nerves; $N=4-6$ animals per group $\left({ }^{*} p<0.05,{ }^{* *} p<0.01,{ }^{* * *} p<0.001,{ }^{* * * *} p<0.0001\right)$.

potential for developmental damage highlights the need for a more specific inhibitor of psychosine synthesis, perhaps an inhibitor of galactosyltransferase. Although several other galactosylated neurolipids require the galactosyltransferase enzyme, fewer lipids would be disrupted compared with L-cycloserine. Regardless, this does not diminish the magnitude of synergy observed when multiple defects are simultaneously targeted.

Even though HSCT carries a significant risk to the patient, it is the current standard of care for GLD. One limitation of HSCT is the slow turnover of hematopoietic-derived microglia in the brain. It has been shown previously that significant engraftment of donor-derived cells in the brains of mice was not observed until $160 \mathrm{~d}$ post-BMT (Kennedy and Abkowitz, 1997), and there is nearly undetectable GALC activity in the brains of $36 \mathrm{~d}$ Twitcher mice treated with BMT at birth (Lin et al., 2007; Reddy et al., 2011; Hawkins-Salsbury et al., 2012b). Due to the aggressive 


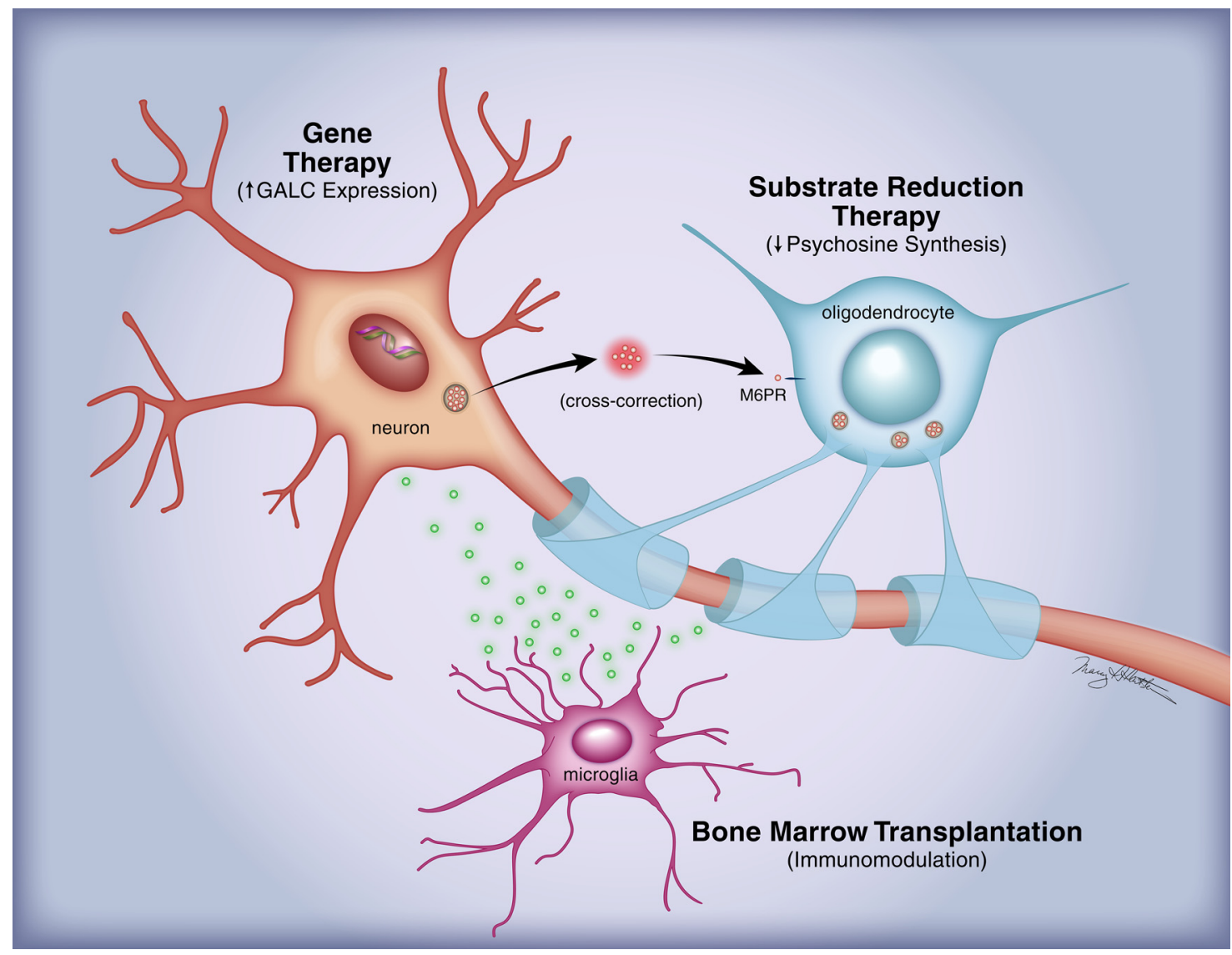

Figure 8. The triple-treatment strategy targets the primary (GALC deficiency) and two secondary (psychosine synthesis and neuroinflammation) consequences of GALC deficiency contributing to globoid cell leukodystrophy. Neurons are efficiently transduced and express high levels of GALC following intracranial injection of an AAV2/5 gene transfer vector. Secreted GALC binds the mannose-6-phosphate receptor (M6PR) on nontransduced cells and is endocytosed through a process referred to as "cross-correction". The endocytosed GALC is targeted to the lysosomes of oligodendrocytes where it degrades psychosine. The substrate reduction therapy drug, L-cycloserine, acts on oligodendrocytes to decrease the synthesis of psychosine. This slows the accumulation of psychosine. Bone marrow transplantation can serve two functions in globoid cell leukodystrophy: (1) it decreases both the disease- and viral vector-associated neurinflammatory response, and (2) it can secrete GALC enzyme as donor-derived microglia reconstitute the CNS.

nature of GLD, it is likely that significant disease develops before a meaningful number of donor microglia can repopulate the CNS and provide therapeutic levels of GALC. Here we demonstrate that although triple-treated Twitcher mice have very few donor cells in the brain at $36 \mathrm{~d}$ of age ( $34 \mathrm{~d}$ post-transplant), the number of donor-derived (GFP-positive) cells increased in the brains of animals that were $>160 \mathrm{~d}$ of age. This could be due to the fact that they lived long enough for significant numbers of donor cells to repopulate the brain. Alternatively, the long-lived animals may have had higher levels of hematopoietic reconstitution from an early age and thus a better long-term outcome. Regardless of the dynamics of CNS engraftment, once donor cells are in the brain, they can serve a dual role by contributing GALC to surrounding tissue and providing an immunomodulatory effect.

Although this therapeutic regimen dramatically increases lifespan and improves behavior, the mice eventually succumb to the disease. One likely explanation for the continued disease progression is that the distribution of the AAV vector, and thus GALC activity, is not sufficient to completely eliminate psychosine in various brain regions. In support of this hypothesis are the persistent, albeit low, levels of psychosine observed in the brains of triple-treated mice. Because psychosine is measured in wholebrain homogenates (or whole-nerve homogenates), it is possible that local concentrations of the lipid could be considerably higher in regions that are inaccessible to GALC. It is known that AAV vectors preferentially infect neurons as opposed to other nonneuronal cells, such as oligodendrocytes. In a disease such as GLD, which severely affects oligodendrocytes and white matter, this could be a significant limitation. Consistent with this hypothesis is the fact that, although myelin levels (LFB staining) appear relatively normal in 36-d-old treated Twitcher mice, the improved myelination does not persist, and myelin staining is dramatically decreased in 160-d-old treated Twitcher mice. Development of more potent or cell-specific vectors may significantly improve outcomes.

Another potential cause for the incomplete clinical response is the increasing neuroinflammation as the tripletreated mice age. Although the levels of various immune mediators in whole-brain homogenates were essentially normalized by triple therapy, CD68 and GFAP expression progressively increase. We also see a progressive increase in PASpositive cells in the white matter tracts of treated Twitcher mice between 36 and $160 \mathrm{~d}$ of age. This apparent discrepancy could be due to localized increases in cytokine/chemokine expression that are masked by low levels of cytokines in relatively large areas of the brain that have little or no inflammation such as the cortex. Regional increases in cytokine/ chemokine expression could be responsible for the localized increases in CD68 and GFAP staining and partial therapeutic response observed in triple-treated animals. 
A prominent feature of GLD is the involvement of the peripheral nervous system. This pathology is reflected in the sciatic nerves of Twitcher mice, which show reduced myelin, decreased axonal density, increased edema, and infiltration of immune cells. Other than lowering psychosine, this triple-treatment regimen appears to have little effect on the disease in the sciatic nerve, which likely contributes to the continued clinical/behavioral decline. This is supported by the poor performance of the tripletreated mice in the wire-hang test, which measures limb strength and serves as a surrogate for the peripheral neuropathy. Interestingly, however, the sciatic nerves of long-lived triple-treated Twitcher mice have histological features referred to as "onionbulb" formations. Onion-bulb formations are typically associated with repeated cycles of demyelination and remyelination suggesting that repair mechanisms may be initiated in the sciatic nerve (Krendel et al., 1989; Naba et al., 2000). Abnormal onionbulb formation has been observed previously in Twitcher mice following high-dose irradiation and BMT (Kagitani-Shimono et al., 2008). However, this histological feature appears to be more widespread in the triple-treated mice. Finally, the continued decline of the triple-treated Twitcher mice could be due to incomplete correction of the autonomic nervous system. It has been shown previously that the autonomic nervous system is affected in Twitcher mice and leads to thymic atrophy and peripheral lymphopenia (Galbiati et al., 2007).

Lysosomal enzymes, including GALC, are ubiquitously expressed. Therefore, deficiencies in these acid hydrolases would be expected to affect many, if not most cells of the body. Not surprisingly, this can activate multiple primary and secondary pathogenic mechanisms. In the case of GLD, targeting a single pathogenic mechanism results in modest to no efficacy. In contrast, synergistic increases in efficacy were observed when the primary defect was targeted with CNS-directed gene therapy and the secondary accumulation of psychosine and neuroinflammation were treated with L-cycloserine and BMT, respectively. It is likely that efficacy will be further increased if additional pathogenic mechanisms are targeted and/or when improved gene transfer vectors and more specific substrate inhibitors are developed. Although the specific parameters will need to be empirically determined on a case-by-case basis, this type of combination therapy provides a promising paradigm upon which to base treatments for this relatively large class of inherited metabolic diseases that are caused by both the primary genetic defect and multiple secondary consequences that affect multiple organ systems.

\section{References}

Biswas S, LeVine SM (2002) Substrate-reduction therapy enhances the benefits of bone marrow transplantation in young mice with globoid cell leukodystrophy. Pediatr Res 51:40-47. CrossRef Medline

Escolar ML, Poe MD, Provenzale JM, Richards KC, Allison J, Wood S, Wenger DA, Pietryga D, Wall D, Champagne M, Morse R, Krivit W, Kurtzberg J (2005) Transplantation of umbilical-cord blood in babies with infantile Krabbe's disease. N Engl J Med 352:2069-2081. CrossRef Medline

Foust KD, Nurre E, Montgomery CL, Hernandez A, Chan CM, Kaspar BK (2009) Intravascular AAV9 preferentially targets neonatal neurons and adult astrocytes. Nat Biotechnol 27:59-65. CrossRef Medline

Galbiati F, Basso V, Cantuti L, Givogri MI, Lopez-Rosas A, Perez N, Vasu C, Cao H, van Breemen R, Mondino A, Bongarzone ER (2007) Autonomic denervation of lymphoid organs leads to epigenetic immune atrophy in a mouse model of Krabbe disease. J Neurosci 27:13730-13738. CrossRef Medline

Galbiati F, Givogri MI, Cantuti L, Rosas AL, Cao H, van Breemen R, Bongarzone ER (2009) Combined hematopoietic and lentiviral gene-transfer therapies in newborn Twitcher mice reveal contemporaneous neurode- generation and demyelination in Krabbe disease. J Neurosci Res 87:17481759. CrossRef Medline

Gentner B, Visigalli I, Hiramatsu H, Lechman E, Ungari S, Giustacchini A, Schira G, Amendola M, Quattrini A, Martino S, Orlacchio A, Dick JE, Biffi A, Naldini L (2010) Identification of hematopoietic stem cell-specific miRNAs enables gene therapy of globoid cell leukodystrophy. Sci Transl Med 2:58ra84. CrossRef Medline

Gray SJ, Foti SB, Schwartz JW, Bachaboina L, Taylor-Blake B, Coleman J, Ehlers MD, Zylka MJ, McCown TJ, Samulski RJ (2011) Optimizing promoters for recombinant adeno-associated virus-mediated gene expression in the peripheral and central nervous system using self-complementary vectors. Hum Gene Ther 22:1143-1153. CrossRef Medline

Hawkins-Salsbury J, Vogler C, Sands MS (2012a) Antioxidant therapy does not improve the course of disease in the murine model of globoid cell leukodystrophy. Exp Neurol 237:444-452. CrossRef Medline.

Hawkins-Salsbury JA, Qin EY, Reddy AS, Vogler CA, Sands MS (2012b) Oxidative stress as a therapeutic target in globoid cell leukodystrophy. Exp Neurol 237:444-452. CrossRef

Hu C, Busuttil RW, Lipshutz GS (2010) RH10 provides superior transgene expression in mice when compared with natural AAV serotypes for neonatal gene therapy. J Gene Med 12:766-778. CrossRef Medline

Hunter DA, Moradzadeh A, Whitlock EL, Brenner MJ, Myckatyn TM, Wei $\mathrm{CH}$, Tung TH, Mackinnon SE (2007) Binary imaging analysis for comprehansive quantitative histomorphometry of peripheral nerve. J Neurosci Methods 166:116-124. CrossRef Medline

Kagitani-Shimono K, Mohri I, Fujitani Y, Suzuki K, Ozono K, Urade Y, Taniike M (2005) Anti-inflammatory therapy by ibudilast, a phosphodiesterase inhibitor, in demyelination of twitcher, a genetic demyelination model. J Neuroinflammation 2:10. CrossRef Medline

Kagitani-Shimono K, Mohri I, Yagi T, Taniike M, Suzuki K (2008) Peripheral neuropathy in the twitcher mouse: accumulation of extracellular matrix in the endoneurium and aberrant expression of ion channels. Acta Neuropathol 115:577-587. CrossRef Medline

Kennedy DW, Abkowitz JL (1997) Kinetics of central nervous system microglial and macrophage engraftment: analysis using a transgenic bone marrow transplantation model. Blood 90:986-993. Medline

Kobayashi T, Yamanaka T, Jacobs JM, Teixeira F, Suzuki K (1980) The Twitcher mouse: an enzymatically authentic model of human globoid cell leukodystrophy (Krabbe disease). Brain Res 202:479-483. CrossRef Medline

Krendel DA, Parks HP, Anthony DC, St Clair MB, Graham DG (1989) Sural nerve biopsy in chronic inflammatory demyelinating polyradiculoneuropathy. Muscle Nerve 12:257-264. CrossRef Medline

Krivit W, Shapiro EG, Peters C, Wagner JE, Cornu G, Kurtzberg J, Wenger DA, Kolodny EH, Vanier MT, Loes DJ, Dusenbery K, Lockman LA (1998) Hematopoietic stem cell transplantation in globoid cell leukodystrophy. N Engl J Med 338:1119-1126. CrossRef Medline

Lee WC, Courtenay A, Troendle FJ, Stallings-Mann ML, Dickey CA, DeLucia MW, Dickson DW, Eckman CB (2005) Enzyme replacement therapy results in substantial improvements in early clinical phenotype in a mouse model of globoid cell leukodystrophy. FASEB J 19:1549-1551. CrossRef Medline

LeVine SM, Pedchenko TV, Bronshteyn IG, Pinson DM (2000) L-cycloserine slows the clinical and pathological course in mice with globoid cell leukodystrophy (twitcher mice). J Neurosci Res 60:231-236. CrossRef Medline

Lin D, Fantz CR, Levy B, Rafi MA, Vogler C, Wenger DA, Sands MS (2005) AAV2/5 vector expressing galactocerebrosidase ameliorates CNS disease in the murine model of globoid-cell leukodystrophy more efficiently than AAV2. Mol Ther 12:422-430. CrossRef Medline

Lin D, Donsante A, Macauley S, Levy B, Vogler C, Sands MS (2007) Central nervous system-directed AAV2/5-mediated gene therapy synergizes with bone marrow transplantation in the murine model of globoid-cell leukodystrophy. Mol Ther 15:44-52. CrossRef Medline

Luzi P, Abraham RM, Rafi MA, Curtis M, Hooper DC, Wenger DA (2009) Effects of treatments on inflammatory and apoptotic markers in the CNS of mice with globoid cell leukodystrophy. Brain Res 1300:146-158. CrossRef Medline

Martin PL, Carter SL, Kernan NA, Sahdev I, Wall D, Pietryga D, Wagner JE, Kurtzberg J (2006) Results of the cord blood transplantation study (COBLT): outcomes of unrelated donor umbilical cord blood transplan- 
tation in pediatric patients with lysosomal and peroxisomal storage diseases. Biol Blood Marrow Transplant 12:184-194. CrossRef Medline

Miyatake T, Suzuki K (1973) Additional deficiency of psychosine galactosidase in globoid cell leukodystrophy: an implication to enzyme replacement therapy. Birth Defects Orig Artic Ser 9:136-140. Medline

Naba I, Yoshikawa H, Sakoda S, Itabe H, Suzuki H, Kodama T, Yanagihara T (2000) Onion-bulb formation after a single compression injury in the macrophage scavenger receptor knockout mice. Exp Neurol 166:83-89. CrossRef Medline

Okabe M, Ikawa M, Kominami K, Nakanishi T, Nishimune Y (1997) "Green mice" as a source of ubiquitous green cells. FEBS Lett 407:313319. CrossRef Medline

Pellegatta S, Tunici P, Poliani PL, Dolcetta D, Cajola L, Colombelli C, Ciusani E, Di Donato S, Finocchiaro G (2006) The therapeutic potential of neural stem/progenitor cells in murine globoid cell leukodystrophy is conditioned by macrophage/microglia activation. Neurobiol Dis 21:314-323. CrossRef Medline

Qin EY, Hawkins-Salsbury JA, Jiang X, Reddy AS, Farber NB, Ory DS, Sands MS (2012) Bone marrow transplantation increases efficacy of central nervous system-directed enzyme replacement therapy in the murine model of globoid cell leukodystrophy. Mol Genet Metab 107:186-196. CrossRef Medline

Rafi MA, Rao HZ, Luzi P, Curtis MT, Wenger DA (2012) Extended normal life after AAVrh10-mediated gene therapy in the mouse model of Krabbe disease. Mol Ther 20:2031-2042. CrossRef Medline

Reddy AS, Kim JH, Hawkins-Salsbury JA, Macauley SL, Tracy ET, Vogler CA, Han X, Song SK, Wozniak DF, Fowler SC, Klein RS, Sands MS (2011) Bone marrow transplantation augments the effect of brain- and spinal cord-directed adeno-associated virus $2 / 5$ gene therapy by altering inflam- mation in the murine model of globoid-cell leukodystrophy. J Neurosci 31:9945-9957. CrossRef Medline

Ripoll CB, Flaat M, Klopf-Eiermann J, Fisher-Perkins JM, Trygg CB, Scruggs BA, McCants ML, Leonard HP, Lin AF, Zhang S, Eagle ME, Alvarez X, Li YT, Li SC, Gimble JM, Bunnell BA (2011) Mesenchymal lineage stem cells have pronounced anti-inflammatory effects in the twitcher mouse model of Krabbe's disease. Stem Cells 29:67-77. CrossRef Medline

Sakai N, Inui K, Tatsumi N, Fukushima H, Nishigaki T, Taniike M, Nishimoto J, Tsukamoto H, Yanagihara I, Ozono K, Okada S (1996) Molecular cloning and expression of cDNA for murine galactocerebrosidase and mutation analysis of the Twitcher mouse, a model of Krabbe disease. J Neurochem 66:1118-1124. CrossRef Medline

Sands MS, Barker JE (1999) Percutaneous intravenous injection in neonatal mice. Lab Anim Sci 49:328-330. Medline

Sands MS, Barker JE, Vogler C, Levy B, Gwynn B, Galvin N, Sly WS, Birkenmeier E (1993) Treatment of murine mucopolysaccharidosis type VII by syngeneic bone marrow transplantation in neonates. Lab Invest 68:676686. Medline

Sundaram KS, Lev M (1985) Inhibition of cerebroside synthesis in the brains of mice treated with L-cycloserine. J Lipid Res 26:473-477. Medline

Suzuki K, Suzuki K (1983) The Twitcher mouse: a model of human globoid cell leukodystrophy (Krabbe's disease). Am J Path 111:394-397. Medline

Wenger D, Suzuki K, Suzuki Y (2001) Galactosylceramide lipidosis: globoid cell leukodystrophy (Krabbe disease). In: The metabolic and molecular basis of disease, Ed 8 (Scriver C, Beaudet A, Sly W, Valle D, Childs B, Kinzler K, Vogelstein B, eds), pp 2669-3694. New York: McGraw-Hill Medical.

Yeager AM, Brennan S, Tiffany C, Moser HW, Santos GW (1984) Prolonged survival and remyelination after hematopoietic cell transplantation in the Twitcher mouse. Science 225:1052-1054. CrossRef Medline 